\title{
Arturo Warman: la lección permanente, la memoria siempre presente
}

\author{
Rolando Cordera Campos
}

Para Tere

$\mathrm{L}$

a muerte de Arturo Warman nos dejó a sus amigos y seguidores una incurable sensación de orfandad. Con él se fueron la razón apacible y la caballerosidad del espíritu, y nos quedaron el recuerdo y el compromiso con el rigor intelectual y la búsqueda sin concesiones de la objetividad en el juicio. Cruzado de la razón histórica, Arturo fue también un aficionado dedicado al cultivo de la razón instrumental de la política social y de la toma de partido clara y sesuda en los debates fundamentales de su tiempo, que sigue con nosotros desafiante e inconcluso. Sus últimas dos obras son un espectáculo fascinante de ejercicio profundo de la crítica de las ideas, las suyas y las de los demás, de demolición de creencias arraigadas y por ello nocivas para la actualización de la política, en dos temas cruciales de la historia moderna de México: el campo mexicano y los indios de México, esclarecedoramente llamados por él los indios mexicanos.

En la segunda y última de sus entregas al pensamiento mexicano sobre México, Arturo Warman nos deja una lección ejemplar de honestidad política y compromiso

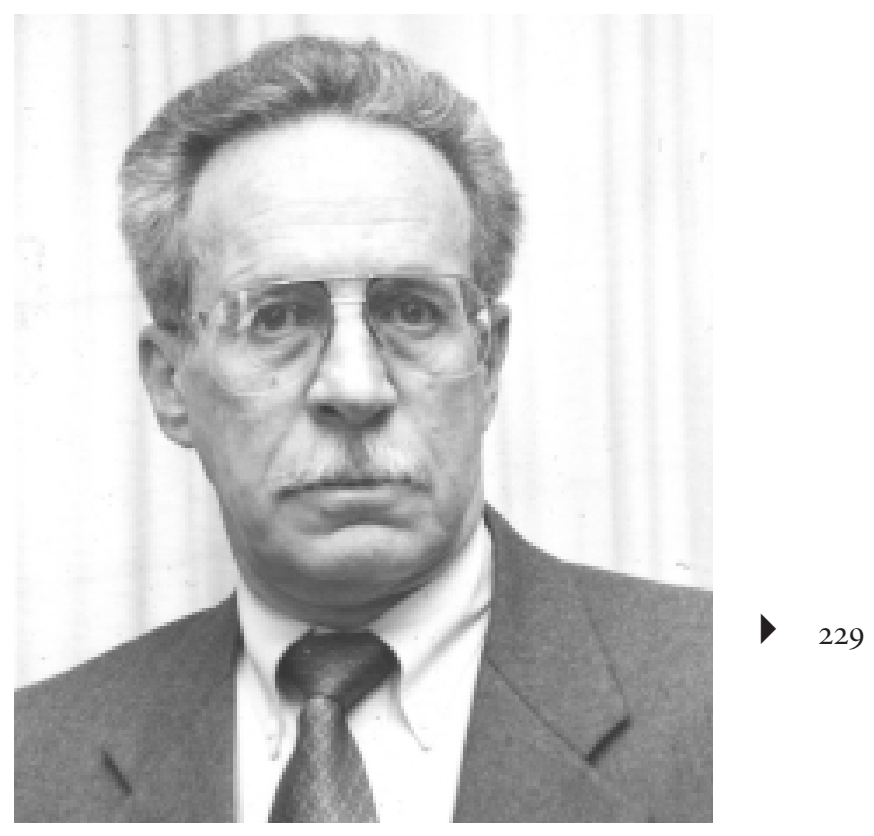

moral e intelectual con sus prójimos tal vez más entrañables, los indios mexicanos. De ellos aprendió toda su vida y sobre su naturaleza siempre en estado de cambio buscó aleccionarnos, para alejarnos del prejuicio y del mito, de la mistificación perniciosa y de la exaltación infundada, fuentes fatales del paternalismo que es, al final de cuentas, una forma más de discriminación y de regodeo en la iniquidad y en el festejo del encierro aldeano disfrazado de respeto a la diversidad.

En su introducción a Los indios mexicanos en el umbral del milenio nuestro querido amigo sabiamente ad-

ROLANDO CORDERA CAMPOS: Facultad de Economía, UNAM.

Desacatos, núm. 14, primavera-verano 2004, pp. 229-234. 


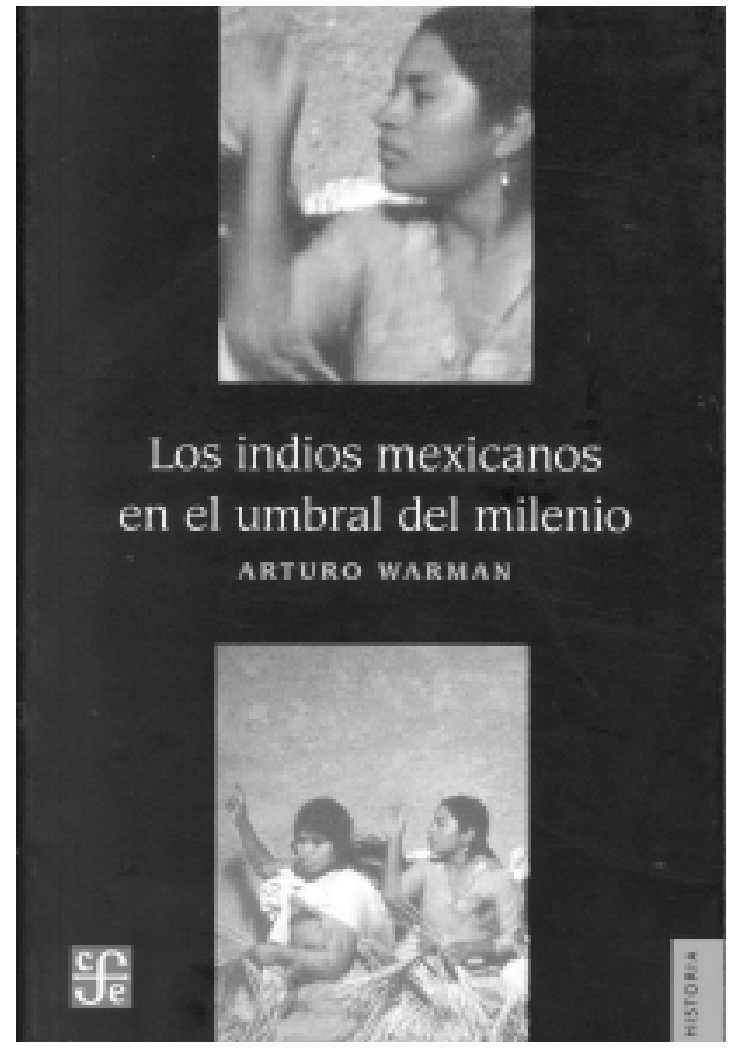

vertía: "el debate nacional sobre el problema indígena, cada vez más ideológico y politizado, no refleja con fidelidad ni con profundidad la compleja realidad de los indígenas mexicanos o sus aspiraciones. Una de las dimensiones que se han perdido de vista o se han olvidado es su enorme diversidad; sin ella, la presencia indígena es sólo una abstracción vacía, una declaración sin contenido" (p. 8). "La pluralidad —añadía— no admite reducción ni simplificación. Los indígenas mexicanos no son una corporación sino un archipiélago lingüístico y cultural... La pluralidad es profunda. De ella derivan riqueza y variedad cultural, múltiples alternativas para la búsqueda de la plenitud y la realización” (p. 9).

No es sólo diversidad lo que califica a este archipiélago humano que adjetiva con toda su fuerza actual y milenaria a la nación mexicana. Debajo de ella están en juego la fragmentación y la desigualdad abismales. Sin asumir esta complejidad, el debate sobre la cuestión indígena queda inconcluso y anclado en conceptos y términos que poco aclaran y en mucho enrarecen la polémica y la toma de decisiones justicieras a la vez que racionales.

En este debate, nos decía nuestro autor, "se prefirieron términos y estereotipos conocidos y arraigados para caracterizar la vida indígena como algo intemporal", cuando lo que ha ocurrido es lo contrario: mudanzas formidables en la demografía, el uso de la lengua y del territorio, los asentamientos y la movilización social a la vez que espacial, nacional y transnacional. "Esos y muchos otros cambios importantes no están presentes en la argumentación que destaca lo antiguo hasta entenderlo como algo permanente, casi irremediable. Sin diversidad ni cambio, frecuentemente se discute sobre la cuestión indígena como algo imaginario" (p. 11).

Debate no resuelto aunque desgastado, el que México ha de tener sobre los indios mexicanos, sigue abierto a la espera de juicios razonados — que no tienen por qué ser resignados- que nos lleven más allá del ruido y del apasionamiento reductivo y enemigo de la política y de la acción colectiva renovadora. Es a esto a lo que Warman nos invitaba y lo que buscaba enriquecer con sus argumentos robustos y sostenidos en una reflexión y una investigación ejemplares, envidiables en el mejor sentido de la palabra. La meta que nos propone debe ser ya la de todos: "abrir el camino para que la diversidad de los indios mexicanos se exprese con libertad y se atienda con justicia, para que ejerza a plenitud sus legítimos derechos en una sociedad respetuosa y tolerante, libre de prejuicios y discriminación. El tema, insistía, no está en las concesiones que debemos hacer en beneficio de los indios sino en la transformación de la sociedad para una mejor y más civilizada convivencia entre sus diversos componentes, cada uno portador de diferencias originales y aspiraciones comunes" (p. 13).

La meta no es inalcanzable y de esto estaba plenamente consciente nuestro amigo. Por eso, y por mucho más, nos harán falta siempre su amable y profunda sabiduría y su enorme convicción intelectual y política acorde con lo mejor del pensamiento nacional y mundial que se propone metas de justicia y reivindicación históricas pero que no entiende que por ellas se deba renunciar a la razón o a admitir las realidades innegables del cambio permanente de la realidad y los grupos humanos. 
No sobra, más bien es obligado, referirnos a algunos de los credos de Arturo y tratar de volverlos nuestros:

Creo en el derecho universal a la diferencia, rechazo el costo de injusticia a que se asocia su ejercicio (p. 11). [...] no busco ni enfatizo lo intemporal o permanente; dudo mucho que esas eternidades se puedan aplicar productivamente a los fenómenos culturales o sociales. Creo que al pasado le debemos realidades actuales y su explicación, conocimientos y lecciones insustituibles, pero no continuidad $[\ldots]$ Creo que hay una correlación positiva entre el conocimiento y las mejores decisiones en todos los campos, sobre todo en la política, en la que la ignorancia se resuelve como intolerancia y brutalidad (p. 13). Rechazo el fundamentalismo: la posesión de la verdad absoluta, revelada, así como su aplicación deductiva [...] pretendí la sencillez para llegar a todos los interesados en el tema y participantes en el debate inconcluso y acorralado de la cuestión indígena. Mi versión es irremediablemente la de un especialista en antropología, pero también es la de un ciudadano. Intenté que la segunda destacara para participar, provocar la reflexión mejor informada y más serena. El desahogo del debate no es una tarea para especialistas sino de los ciudadanos. Entre ellos están, de manera ineludible y destacada, los indios mexicanos (p. 13).

En adelante, como un mínimo, preliminar homenaje a Arturo Warman, ofrezco una versión revisada de mi intervención en la presentación de su otra obra magna, $E l$ campo mexicano en el siglo XX (Fondo de Cultura Económica, México, 2001). En este libro fundamental se cuenta una historia que es, todavía, no sólo nuestra historia sino parte viva, acuciante, de nuestro incierto presente. Es mucho lo que tenemos que aprender de Arturo; su memoria será un presente exigente para muchos de nosotros por mucho tiempo.

\section{LOS CAMPESINOS MEXICANOS Y SU CONSTRUCCIÓN DEL SIGLO XX}

El campo mexicano en el siglo XX es un libro importante, decisivo para esta época de sumas, restas y combinaciones políticas y estructurales en que hemos entrado. Es un texto repleto de información relevante y pertinente, que con eficacia soporta $y$, a veces, abruma una argumentación sostenida, implacable, que busca sombras donde algunos solían ver sólo luces, y anuncia luces donde muchos no vemos sino sombras, claroscuros, que al fin del siglo y el ciclo revolucionario mexicano parecen más bien nubarrones cargados de electricidad y anuncios de tormenta.

En siete apretados capítulos, varios de ellos densos y avasalladores por la información, los datos y las cifras que avanzan sobre el lector descuidado y el especulador cínico o escéptico, Warman monta un relato fundamental sobre lo que fue y ha sido el campo mexicano, sobre lo que hicimos de él y de los campesinos del siglo XX. La historia que nos relata Warman se arriesga a hablar de lo que pudo haber sido la sociedad rural mexicana emanada y recreada por la Revolución, en alguna de las varias coyunturas históricas que marcaron su devenir y, en el grand finale del volumen, el relato se torna horizonte y nos convoca a reflexionar prospectivamente sobre lo que este campo y sus todavía muchos pobladores pueden ser en los primeros decenios del siglo y el milenio que empiezan.

El campo: el gran desconocido de la historia del desarrollo moderno mexicano, la fuente siempre abusada de los discursos o del folclor, así como el objeto preferido de la burla o el olvido, cuyos personajes y figuras tocaron a la puerta de los poderes constituidos en estos días de nuevo con impertinencia, es presentado por su biógrafo como un escenario viviente, cargado de cultura y política, de abuso y demagogia, de grandilocuencia y obsesión por sobrevivir los muchos quiebres de las modernizaciones desde arriba y los requiebres producidos desde abajo. El campo y sus habitantes, los campesinos y los peones, los hacendados y los neolatifundistas, los burócratas agrarios y los políticos de ocasión y no, de temporal o riego, conforman un hábitat asombroso, despojado de y ajeno a cualquier determinismo, donde la tierra, su reparto mayúsculo y su propiedad pulverizada a la vez que concentrada, la producción y su distribución, la movilización de las masas y su manipulación por los que mandaban, la incorporación subordinada del campesinado pero al final de cuentas nunca su anulación como fuerza social, proclamada por la estrategia de moda de algún cambio estructural protagonizan una centralidad sociológica indiscutible, que también fue centralidad política real, no sólo discursiva, durante un buen tramo del siglo XX mexicano. 
El autor describe con precisión el desplazamiento de esa centralidad que, sin embargo, no es sólo resabio del pasado: sin entenderla y sin tomarla en cuenta en lo que vale y pesa es y será imposible comprender cabalmente el siglo mexicano de la Revolución.

Tal vez el fin de ese ciclo que hoy empezamos a registrar tampoco sea inteligible sin recurrir con detalle y rigor crítico, también con pasión, a esta historia accidentada, sinuosa y espiral que Arturo Warman consiguió trazar magistralmente, sin renunciar a su peculiar, sin duda respetable y en mucho compartible compromiso con la acción política e institucional. No sobra decir que éste fue un compromiso siempre vigilado por el gran amarre con el rigor y el respeto intelectuales que Arturo cultiva y que a la vez merece como el que más.

Nuestro autor nos ofrece un relato cautivador, me atrevería a decir que apasionado si no temiese traicionar la intención más transparente o aparente del libro, que responde a aquella imaginación antropológica que tan bien cultivaron en el pasado Warman y varios de sus coetáneos, y que tanta envidia (de la buena) provocó en sus lectores y estudiosos de las otras ciencias sociales. Esta imaginación pudo, en ciertos casos, apoderarse de la imaginación política y el activismo social para darle a la disciplina matriz una autoridad y un estatuto que ya en aquellos años duros del pos 68 muchos empezaban a regatearle, so capa de un marxismo mal entendido y peor aplicado. La verdad escueta es que hasta la publicación de este texto miliar muchos echábamos de menos esta manera de contar y de adentrarse en los vericuetos de esta endiablada sociedad compleja y diversa, sin perder de vista precisamente eso: una complejidad y una variedad irreductibles, incluso inconmensurables.

Este es un relato sabroso (y quienes pudieron disfrutar de la dialéctica warmaniana alrededor de un buen mezcal o un mejor whisky me entenderán sin problemas), que se trenza sin dificultad con la multitud de datos y cifras que el libro contiene y que dan sustento a los aciertos y las provocaciones nada escondidas del autor, a las explicaciones a veces sorprendentes, a las defensas sólidas, sin duda discutibles, de las decisiones de política en que le tocó participar. De estos vericuetos el relato siempre sale airoso, con sus aciertos retóricos y persua- sivos, su razonamiento tranquilo pero implacable, con sus desplantes y su invitación a la discrepancia, que no sólo adornan un volumen ejemplar sino que lo llenan de vida y motivos serios para una reflexión de mayor alcance y plazo que lo que una presentación y una invitación a leerlo permiten.

Insisto en que se trata de un libro decisivo sobre el tema, pero que no será, espero, un canon ni la última palabra sobre la cuestión agraria y sus derivados de producción y mercado, confrontación social y desafío puntual a una modernización siempre inconclusa. Quiero estar seguro de que esta obra, además de ser estudiada y usada cotidianamente por estudiosos y estudiantes del pasado y del presente mexicanos, así como por aquellos que quieren acercarse al futuro por construir, será también la fuente de un debate caliente entre los contingentes de ayer y hoy que entendieron y entienden que lo que México fue, es y puede ser inseparable de esta saga dolorosa, multitudinaria, compleja y abigarrada que nos cuenta Arturo Warman con el pretexto de describirnos al campo mexicano del siglo XX.

\section{ACIERTOS, DISCREPANCIAS, SIMPATÍAS PELIGROSAS}

Tomo, casi al azar, unos cuantos ejemplos de lo que he llamado aciertos, invitación a discrepar, simpatías peligrosas, por atractivas pero a la vez cargadas de incertidumbre o fragilidad.

Empecemos por los aciertos, que son muchos y que aquí son apenas ilustraciones seleccionadas un tanto arbitrariamente. Warman pone de relieve, con abundancia de datos y referencias, la centralidad que alcanzó el campo mexicano en el siglo XX. Se trató de una centralidad de "larga duración" que cruza prácticamente todo el periodo de la posrevolución. No es, así, una mera constatación o curiosidad estadística; nos refiere a una problemática cuyo tratamiento llevó al Estado a reproducir en el discurso, sin consideración estratégica alguna, dicha centralidad, a pesar de que la sociedad concreta y su civilización material iban ya, en especial a partir de la década de 1960, claramente por otro lado. Esta reproducción se volvió 
una mitificación que llevó a mistificar decisiones y estadísticas de modo portentoso, y que no ha encontrado una tersa solución de continuidad en las relaciones políticas fundamentales ni en las concepciones oficiales y no oficiales sobre el desarrollo del país. Nuestro autor es optimista respecto de los efectos de racionalidad y transparencia que el TLC y la reforma del artículo 27 traerán a la larga, pero eso está todavía por verse y sortearse.

En la década de 1970, cuenta Arturo, "el reparto agrario había alcanzado una dimensión mítica en la clase política... (p. 68). Más adelante (pp. 120-121) nos relata:

En el sexenio 1976-1982 se modificaron al alza todas las estadísticas de producción del sector agropecuario alegando una actualización técnica. La modificación fue demasiado optimista si no es que francamente imaginativa... En la década de 1970 [...] no se registró ningún año de disminución en el producto agropecuario y en los últimos tres años de la década el incremento anual fue mayor al $5 \%$. Con esas cifras sólidas y alentadoras [concluye] resulta un poco inquietante que en 1981 se lanzara el Sistema Alimentario Mexicano para rescatar con cuantiosos e insostenibles subsidios a un sector postrado... La bonanza estadística estuvo y quedó marcada por la sospecha y la desconfianza.

En el libro se describe y explica al detalle y a fondo la profundidad de la reforma agraria, junto con la enorme carga de pobreza con que la sociedad rural inició el siglo XX. Son también parte importante de su argumento las paradojas y jugarretas de la demografía, en su relación con la propiedad y con la dinámica social del campo "reinventado" por la Revolución. Todo se pone de nuevo en juego cuando asumimos la demografía, las edades y el género, como variables activas de la evolución del México rural. Warman llama nuestra atención sobre esto con eficacia conceptual y numerológica.

Vayamos ahora a algunas discrepancias. Apenas arrancado el relato, se nos presenta un argumento discutible, sobre todo a la luz de los acontecimientos posteriores de la reforma estructural. "De manera implícita pero nítida [sostiene Arturo con seguridad y no sin audacia] la reforma de 1992 replanteó la relación entre la propiedad social, sus sujetos, el gobierno y el mercado... El tránsito no ha sido fácil ni está completo, pero las bases del

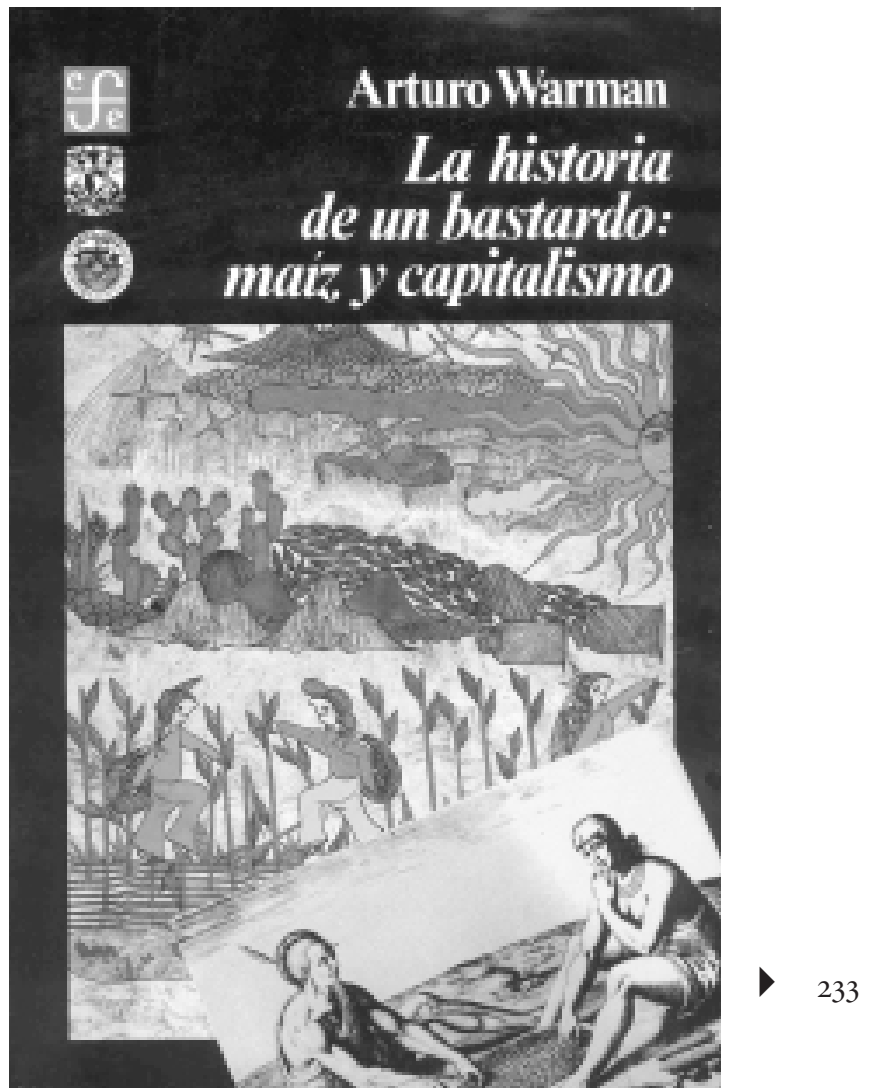

desarrollo del campo se modificaron por segunda vez en este siglo" (p. 22). La nitidez de lo implícito es, en política, siempre cuestionable, pero lo es más cuando se trata de una reforma como la que se comenta.

Esta reforma, recordémoslo, se implanta a partir de un consenso más que hipotético, que llevó a decisiones que no se consultaron ni, al parecer, buscaban sostenerse en una hegemonía renovada del Estado. Esta hegemonía se daba por hecho, suponiendo, tal vez, el cansancio de los héroes de la leyenda agraria cuya liberación se buscaba y prometía. Sin duda, el reformismo no puede realizarse sin el Estado, pero es claro que el Estado requería ya entonces con urgencia de una legitimidad que no dependía más, ni principalmente, del desempeño o de los resultados, mucho menos del legado de la tradición revolucionaria que, como comentamos arriba, había dado lugar ya a una mitología. Estos resultados estaban, en realidad siguen estando, en el futuro. 
El modo aséptico y la distancia con que el autor evalúa y compara el régimen de subsidios y su temporalidad, merece una discusión mayor, pero vale la pena dejarlo apuntado desde ahora. Tal vez, la ronda mayor sobre esta cuestión vaya a darse en la mesa de la confrontación social y política, una vez que termine el periodo de gracia del TLC, y no sólo en la tranquilidad del juicio académico o memorioso. En todo caso, antes de que este destino nos alcance los campesinos y productores del campo realmente existentes han hecho llegar a la sociedad urbana (que también sufre los efectos de un cambio sin progreso social y con estancamiento económico prolongado) más de una señal y una llamada de urgencia. Lo que sigue lo veremos pronto.

Las promesas de la reforma del artículo 27 siguen en el horizonte del (in)cumplimiento, junto con otras ofertas mayores asociadas al cambio estructural. De cualquier modo, hoy resulta difícil ser optimista. Hablar, por ejemplo, de una recuperación del crecimiento del PIB agropecuario que no supera el crecimiento de la población es esperar demasiado, si, además, se atiende a la composición real y en perspectiva de esta un tanto ilusoria recuperación (véase pp. 139-140; 179-188).

Aterricemos en nuestras simpatías. El desafío, propone Arturo Warman, es superar, dejar atrás para siempre la pobreza inicua que marca la sociedad rural y su extraordinaria saga. Sin embargo, nos advierte, nada de esto puede siquiera plantearse sin admitir y asumir con rigor que "la diversidad es condición abrumadora del campo mexicano. La medicina que en algún lugar cura en otro enferma, mata o es inocua...".

Por otra parte —nos dice Warman — las múltiples acciones que reclama la diversidad no pueden darse si no es a partir de decisiones y pactos generales. Los mexicanos [lo plantea con claridad y autoridad] tenemos que decidir si queremos crecimiento rural porque nos va a costar. La decisión debe sostenerse en el tiempo o será inútil si no es que perjudicial. La historia, que es experiencia, lo muestra. El desarrollo del campo es asunto serio, cobra caro las improvisaciones y las ocurrencias (p. 142).

Antes de una breve pero espléndida "nota bibliográfica" al final del libro, se nos ofrece un atisbo ilustrado hacia el futuro, con base en tres escenarios: uno catastrófico, otro moderadamente pesimista y uno optimista. Predecir el futuro social, nos alerta Arturo, es inútil, es una imposibilidad. Por eso

se recurre al porvenir como un método. Se proyectan tendencias reseñadas [...] hasta su conclusión o máxima expansión para destacar su impacto... [Esta] proyección genera un escenario en el sentido teatral de la palabra, una ficción. Esa construcción imaginaria puede provocar apoyo, rechazo, incredulidad o indiferencia, posiciones y definiciones inmediatas. Precisamente de eso se trata, de motivar reacciones que apoyen la construcción de un futuro mejor (p. 222)

Sobre advertencia no hay engaño y Arturo Warman lo logra: rechazo a la catástrofe; cercanía obligada por los años, con la moderación pesimista; simpatía, repito que "peligrosa", con el optimismo. Indiferencia nunca, porque ni el tema ni el libro lo permiten, salvo que uno se empeñe en vivir en Kafkahuamilpa.

Hay condiciones reales para continuar y profundizar la transformación de la sociedad rural... Si todos o parte de esos cambios y mucho más sucedieran en las políticas públicas para el campo, ¿cómo sería este escenario? Pues precisamente optimista.

Con una dinámica de crecimiento compartido y sostenido, sin barreras que lo impidan, con una población más pequeña dedicada a las actividades agropecuarias $[\ldots]$ con ingresos en crecimiento en una economía rural diversificada y dinámica. Con regiones fortalecidas por su diversidad, por su oferta irrepetible. Un campo con productores jóvenes desplegando iniciativas y corriendo riesgos, con asociaciones activas y democráticas. Un campo con minifundios desmoronándose por las buenas y de mil maneras. Un campo con oportunidades y esperanzas.

No sería el paraíso ni Jauja... Ni el campo sería siempre verde ni las vaquitas felices estarían pastando en él; el escenario no ofrece felicidad [...] propicia que los productores y trabajadores rurales tomen en sus manos su desarrollo; permite avanzar en la igualdad de oportunidades para la gente del campo. En este escenario no se alcanza la utopía pero se rompe la condena. Ciertamente no es un propósito modesto.

No lo es, pero vale la pena acariciarlo.

Manzanillo, Colima, 25 de abril de 2004. 